\title{
Protein Kinase C- and Reactive Oxygen Species-Dependent Stimulation of Intracellular CAMP in Human Eosinophils
}

\author{
The Role of Extracellular Signal-Regulated Protein Kinases
}

\author{
Charles I. Ezeamuzie Najla Taslim
}

Department of Pharmacology and Toxicology, Faculty of Medicine, Kuwait University, Kuwait

\author{
Key Words \\ Eosinophils · cAMP · Signal transduction - Protein kinase C . \\ Reactive oxygen species $\cdot$ Phorbol myristate acetate $\cdot$ \\ ERK $1 / 2$
}

\begin{abstract}
Objective: The objective of this study was to investigate the role of the extracellular signal-regulated protein kinases 1 and $2($ ERK1/2) in the signalling pathway of the novel protein kinase C (PKC)- and reactive oxygen species (ROS)-dependent stimulation of intracellular adenosine $3^{\prime}, 5^{\prime}$-cyclic monophosphate (CAMP) production in human eosinophils. Materials and Methods: Immunomagnetically purified human eosinophils were stimulated in vitro with a PKC activator, phorbol myristate acetate (PMA), and the CAMP response in the presence of a phosphodiesterase inhibitor, rolipram, was determined. The role of ERK1/2 phosphorylation was investigated using specific inhibitors and Western blot analysis. Results: The PMA-stimulated eosinophils responded with a profound increase in intracellular levels of CAMP that was dependent on both PKC and ROS, as confirmed by the use of specific inhibitors: Ro 31-8220 for PKC and diphenyleneiodonium (DPI) for the ROS-generating enzyme NADPH oxidase. Pre-treatment of cells with the ERK1/2 inhibitor PD 98059, but not the p38-MAPK inhibitor SB203580, nor the PI3 kinase inhibitor, wortmannin, abolished the response. PMA treat-
\end{abstract}

ment induced the phosphorylation of ERK1/2 with a time course that is consistent with a role in the CAMP response. The ERK $1 / 2$ phosphorylation was abolished by the ERK1/2 inhibitor PD 98059 and the PKC inhibitor Ro 31-8220, but not the NADPH oxidase inhibitor DPI. Conclusion: These results reveal the involvement of ERK1/2 in the signalling mechanism of PMA-stimulated, PKC- and ROS-dependent stimulation of CAMP production in human eosinophils, and show that ERK1/2 phosphorylation is upstream of ROS production in the signalling pathway.

Copyright $\odot 2008$ S. Karger AG, Basel

\section{Introduction}

Eosinophils are known to play important roles in the pathophysiology of allergic diseases $[1,2]$. In asthma, for example, eosinophils infiltrating the lungs are activated to release tissue-damaging granule proteins as well as a variety of other mediators, such as ROS, leukotrienes and cytokines, all of which contribute to the bronchial inflammation, hyperresponsiveness and airway remodeling that collectively constitute the hallmark of asthma $[3,4]$.

When appropriately stimulated eosinophils release a large amount of ROS, especially superoxide anions $\left(\mathrm{O}_{2}^{-}\right)$and hydrogen peroxide $\left(\mathrm{H}_{2} \mathrm{O}_{2}\right)$. The most effec-

\section{KARGER}

Fax +4161306 1234

E-Mail karger@karger.ch

www.karger.com
(C) 2008 S. Karger AG, Basel

1011-7571/08/0176-0468\$24.50/0

Accessible online at:

www.karger.com/mpp
Prof. Charles I. Ezeamuzie

Department of Pharmacology and Toxicology

Faculty of Medicine, Kuwait University

PO Box 24923, Safat 13110 (Kuwait)

Tel. +965 498 6329, Fax +965 531 8454, E-Mail ezeamuzie@hsc.edu.kw 
tive stimuli that activate ROS generation in eosinophils include platelet-activating factor (PAF), interleukin-5 (IL-5), granulocyte-macrophage colony-stimulating factor (GM-CSF) as well as phorbol 12-myristate 13-acetate (PMA) - a well-known activator of protein kinase C [5, 6]. In leukocytes and many other cell types, most of the ROS is generated by the action of the enzyme NADPH oxidase. The enzyme catalyzes the transfer of electrons from $\mathrm{NADPH}$ to molecular $\mathrm{O}_{2}$, reducing it to $\mathrm{O}_{2}^{-}$, which may further be converted to $\mathrm{H}_{2} \mathrm{O}_{2}$ by the superoxide dismutase [7].

There is increasing evidence that ROS may act as signaling intermediates in a variety of cellular responses, such as gene transcription $[8,9]$, activation of signaling kinases $[10,11]$ and antigen-IgE-induced mast cell degranulation and leukotrienes release [12].

Cyclic AMP is a second messenger that potently inhibits many leukocyte pro-inflammatory responses such as gene transcription, adhesion, degranulation, chemotaxis and respiratory burst $[5,13-15]$. It also mediates the smooth muscle relaxing effect of many bronchodilators. Thus, the elevation of intracellular cAMP remains a viable strategy for the development of anti-allergic and anti-inflammatory drugs.

Recently, we reported that PMA is able to stimulate the production of intracellular cAMP in isolated human eosinophils [13]. The response, unlike the $\mathrm{G}_{\mathrm{s}}$-dependent histamine-induced stimulation of cAMP, is calcium-insensitive and completely dependent on PKC and NADPH oxidase activation $[13,14]$. However, both the details and the sequence of biochemical events downstream of PKC activation, leading to the activation of adenylyl cyclase (AC) in eosinophils, have not been clarified.

Mitogen-activated protein kinases (MAPK) are critical signaling kinases involved in the activation of many cell types $[16,17]$. There are at least 3 MAPK pathways the p44/p42 MAPK (or ERK1/2), the c-Jun kinase and the p38-MAPK pathways - all of which often operate in parallel and, in some cell types, independently [16]. Although the activation of $\mathrm{PKC}$ is known to result in the phosphorylation of a wide range of proteins and kinases including the MAPK family $[18,19]$, it is not known whether or not the phosphorylation of the key signaling kinases such as ERK1/2 and p38-MAPK are involved in the PKC-dependent stimulation of intracellular cAMP in human eosinophils.

The purpose of this study was, therefore, to investigate the involvement of ERK1/2 phosphorylation in the sequence of events downstream of PKC activation leading to cAMP production in human eosinophils.

ERK1/2 Mediates PKC- and

ROS-Dependent cAMP Production

\section{Materials and Methods}

\section{Materials}

The following drugs and reagents were obtained from SigmaAldrich, (St. Louis, Mo., USA): percoll, HEPES buffer, DPI, PMA, bovine serum albumin (BSA), histamine dihydrochloride, rolipram, Ro 31-8220, PD98059, SB203580, wortmannin and all inorganic salts. Mouse monoclonal anti-human CD16 antibody (clone FcR gran1) was obtained from CLB (Amsterdam, Netherlands), while the magnetic beads were supplied by Dynal (Oslo, Norway). The cAMP assay kit (direct method) was obtained from Assay Designs (Ann Arbor, Mich., USA). The anti-ERK1/2 and anti-phospho-ERK1/2, as well as the horseradish peroxide-labelled secondary goat anti-rabbit IgG antibodies were obtained from Santa Cruz Biotechnology (Santa Cruz, Calif., USA). The antibodies were all polyclonal.

Stock solutions of all water-insoluble drugs were made in DMSO (dimethyl sulfoxide) to concentrations in the range of $100-400 \mathrm{~mm}$ and then diluted directly in buffer. The final concentration of the solvent did not exceed $0.05 \%$ - a concentration that had no significant effect on eosinophil responses.

\section{Isolation of Blood Eosinophils}

Fresh blood was obtained from consenting individuals who were mildly atopic, but had no allergic disease nor taken any medication in the last $72 \mathrm{~h}$. The protocol for the study was reviewed and approved by the Ethics Committee of the Faculty of Medicine, Kuwait University, Kuwait. Granulocytes were isolated from sodium-citrate-anti-coagulated (13 $\mathrm{mm}$ final) blood by erythrocyte sedimentation, followed by percoll gradient centrifugation as previously described [20]. The granulocytes were washed twice in 'wash buffer' $\left(\mathrm{Ca}^{2+}\right.$ - and $\mathrm{Mg}^{2+}$-free HEPES-buffered Hank's balanced salt solution containing $0.25 \% \mathrm{BSA}, \mathrm{pH}=7.3$ ) and re-suspended in the same buffer at $2 \times 10^{7}$ cells $/ \mathrm{ml}$. Eosinophils were finally purified by the immunomagnetic method, as previously described [21]. The purified cells were recovered by centrifugation, washed twice and then re-suspended in 'reaction buffer' ('wash buffer' containing $2 \mathrm{mM} \mathrm{Ca}^{2+}$ and $1 \mathrm{mM} \mathrm{Mg}^{2+}$ ) for experiments. The eosinophil purity was assessed by differential count of a Wright-Giemsa-stained cytosmear and was regularly greater than $98 \%$. Viability was determined by trypan blue exclusion and always exceeded $98 \%$.

\section{Intracellular Cyclic AMP Determination}

Eosinophils, re-suspended at a concentration of $10^{7}$ cells $/ \mathrm{ml}$ in BSA-free reaction buffer, were dispensed in $50-\mu l$ aliquots into each well of a 96-well plate. Then, $100 \mu \mathrm{l}$ of reaction buffer containing rolipram $(10 \mu \mathrm{M})$ and test drugs $(2 \times$ final concentrations), where indicated, were added. After incubating the mixture for 10 $\min$ (or as otherwise stated) at $37^{\circ} \mathrm{C}$, the reaction was started by the addition of $50 \mu \mathrm{l}$ of warmed stimuli or vehicle. Three minutes later - a time found to be optimal for this response - the reaction was stopped by the direct addition of $22.2 \mu \mathrm{l}$ of $1 \mathrm{~N} \mathrm{HCl}$. After a thorough mixing and a further incubation for $10 \mathrm{~min}$, the plate was centrifuged at $1,500 \mathrm{~g}$ for $10 \mathrm{~min}$ and $200 \mu \mathrm{l}$ of the supernatant was taken and stored at $-43^{\circ} \mathrm{C}$ pending cAMP assay.

Cyclic AMP levels were measured, after acetylation, using a commercially available enzyme immunoassay kit (Assay Designs, Ann Arbor, Mich., USA), and following the manufacturer's instructions. The sensitivity of the assay was $0.01 \mathrm{pmol} /$ well. 

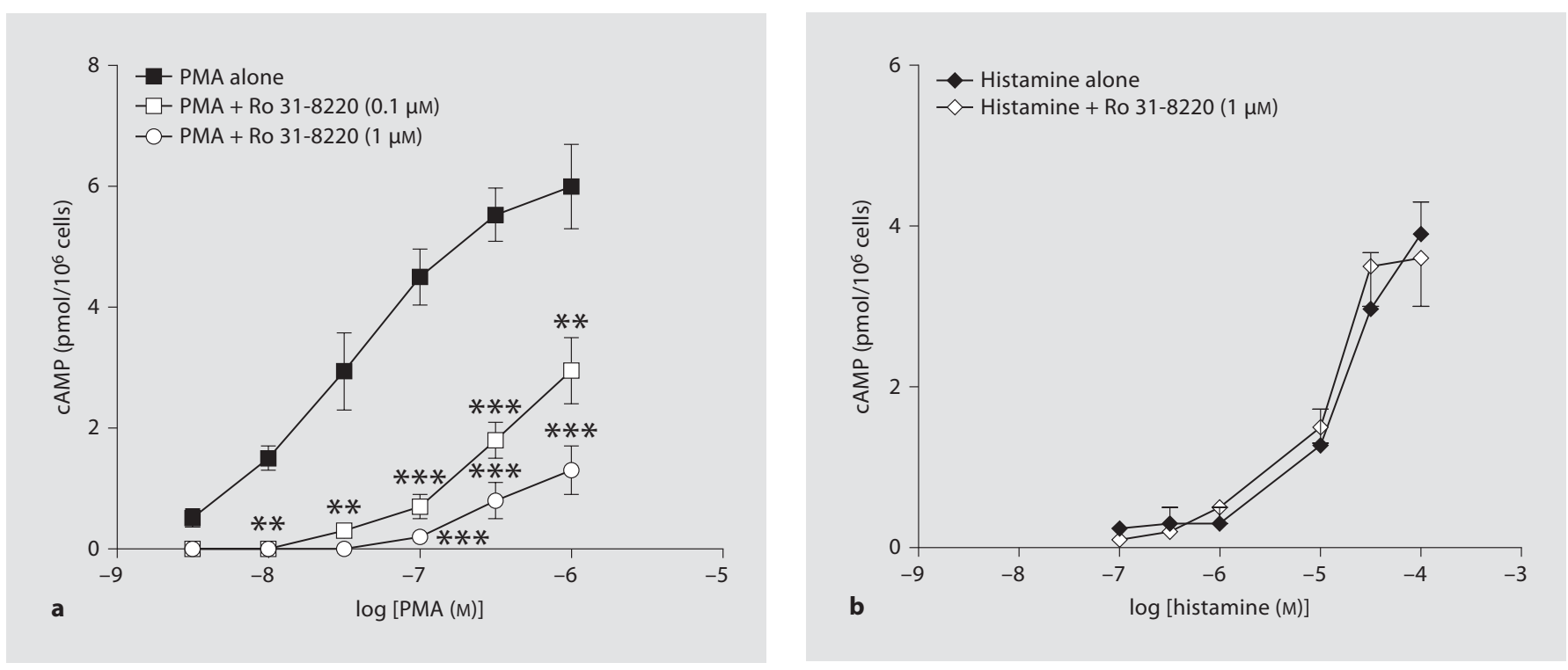

Fig. 1. Stimulation of cAMP production in eosinophils by PMA (a) and histamine (b), and the effect of the PKC inhibitor Ro 31-8220. Cells were pre-incubated with or without Ro 31-8220 for 5 min, followed by rolipram $(5 \mu \mathrm{M})$ for another $5 \mathrm{~min}$, before being stimulated for $3 \mathrm{~min}$ with PMA or histamine. Values are means $\pm \mathrm{SE}$ for 8 experiments. Basal releases (in the presence of rolipram) of $0.2-0.4 \mathrm{pmol} / 10^{6}$ cells have been subtracted from all values. ${ }^{* *} \mathrm{p}<0.01 ;{ }^{* *} \mathrm{p}<0.001$.

\section{Immunoblotting}

Purified eosinophils $\left(10^{7}\right.$ cells $\left./ \mathrm{ml}\right)$ were lysed with sodium dodectyl sulphate (SDS) sample buffer [2\% SDS, $375 \mathrm{~mm}$ Tris/ $\mathrm{HCl}$, (pH 6.8), 4\% $\beta$-mercaptoethanol, 0.1\% bromophenol blue and $25 \mathrm{~mm}$ dithiothreitol] and the lysate was boiled for $10 \mathrm{~min}$. Equivalents of $7.5 \times 10^{5}$ cells were then loaded per lane of $8 \%$ polyacrylamide gel containing $0.1 \%$ SDS (SDS-PAGE) and electrophoresed. Proteins were subsequently electroblotted onto nitrocellulose membranes [Amersham, Upsulla, Sweden; enhanced chemiluminescence (ECL) grade]. Blots were blocked in blocking buffer $(100 \mu \mathrm{M}$ Tris-HCl, $150 \mathrm{mM} \mathrm{NaCl}$ and $0.1 \%$ Tween 20, $\mathrm{pH}$ 7.5 ) containing $5 \%$ non-fat dry milk powder for $30 \mathrm{~min}$ at room temperature and washed 5 times in blocking buffer. The separated proteins were then probed with commercially available antibodies to ERK1/2 and phosph-ERK1/2 for $2 \mathrm{~h}$. After 5 washes in PBS, blots were incubated with horseradish peroxidase-conjugated goat anti-rabbit secondary antibody (diluted 1:200$1: 1,000)$ for $1 \mathrm{~h}$ at room temperature. Immunoreactive blots were then detected by the ECL detection kit (Amersham) and recorded on Kodak X-OMAIS-s film (Sigma-Aldrich). The ECL reaction time was 1-2 min for total ERK and 10-15 min for phosphoERK.

\section{Statistical Analysis}

Experimental data are presented as means \pm SE. Drug concentrations producing $50 \%$ of the maximal increase in intracellular cAMP levels, (EC $\mathrm{E}_{50}$ values), or $50 \%$ inhibition of response $\left(\mathrm{IC}_{50}\right.$ values), were calculated from the concentration-effect curves by non-linear regression analysis using GraphPad InPlot (GraphPad Software, Philadelphia, Pa., USA). Differences between means were analyzed by analysis of variance (ANOVA) fol- lowed by Dunnett's test or by one-sample t test as appropriate (InStat, GraphPad). Differences were considered statistically significant at $\mathrm{p}<0.05$.

\section{Results}

\section{Stimulation of Intracellular cAMP Production by PMA} and Its Dependence on PKC

The PMA induced a pronounced concentration-dependent generation of cAMP in eosinophils as shown in figure 1 . The agent produced a maximal response that was comparable to that of histamine in magnitude, but was about 400 times more potent. Pre-treatment of the cells with the general PKC inhibitor Ro 31-8220 resulted in a strong concentration-dependent inhibition of the cAMP response (fig. 1a). In contrast, the effect of histamine was completely unaffected (fig. 1b); thus, confirming the specificity of the PKC involvement in the PMAinduced cAMP response.

\section{Dependence of PMA-Induced cAMP Production on Intracellular Reactive Oxygen Species}

The role of reactive oxygen species (ROS) in PMA-induced cAMP generation was confirmed with DPI, the well-known inhibitor of the ROS-generating enzyme 


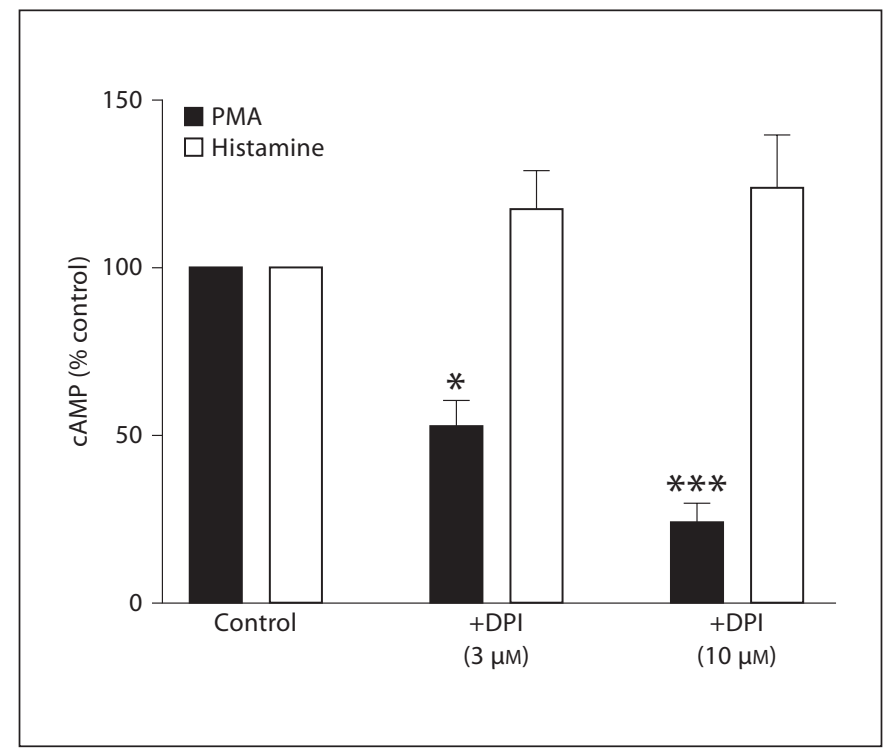

Fig. 2. The effect of DPI on the cAMP response in eosinophils stimulated with PMA or histamine. Cells were incubated with the inhibitors for $5 \mathrm{~min}$, followed by rolipram $(5 \mu \mathrm{M})$ for another $5 \mathrm{~min}$, before being stimulated for an additional $3 \mathrm{~min}$ with PMA $(200 \mathrm{nM})$. Values are means \pm SE for 4 experiments. The control (uninhibited) cAMP releases were in the range of 2.4-5.6 $\mathrm{pmol} / 10^{6}$ cells. ${ }^{*} \mathrm{p}<0.05 ;{ }^{* *} \mathrm{p}<0.001$.

NADPH oxidase. As shown in figure 2, treatment of the cells with DPI resulted in a strongly significant inhibition of the cAMP response to PMA, with the concentration of $10 \mu \mathrm{M}$ achieving $76 \pm 7 \%$ inhibition. In contrast, a similar treatment failed to inhibit histamine-induced cAMP production, but rather increased it.

The Role of ERK1/2 Activation in the Signaling Pathway of PMA-Stimulated, ROS-Dependent cAMP Production in Eosinophils

Because PMA is known to produce some of its effects by phosphorylating ERK1/2, we investigated whether or not phosphorylation of these enzymes was involved in the signaling pathway of the PMA-induced cAMP response. As shown in table 1, pre-treatment of the cells with the inhibitor of ERK1/2, PD 98059, caused a significant and concentration-dependent inhibition of the cAMP response, with $50 \mu \mathrm{M}$ achieving an inhibition of about $82 \%$. In contrast, the histamine-induced cAMP response was completely unaffected by this treatment. A similar treatment of the cells with SB 203580, at concentration ranges $(1-10 \mu \mathrm{M})$ known to specifically inhibit the p38-MAPK or wortmannin $(0.1-1.0 \mu \mathrm{M})$, a
Table 1. Effect of various inhibitors of signaling kinases on cAMP response induced by PMA and histamine in human eosinophils

\begin{tabular}{lcc}
\hline \multirow{2}{*}{ Inhibitors } & \multicolumn{2}{c}{ cAMP response (\% of control value) } \\
\cline { 2 - 3 } & PMA $(200 \mathrm{nM})$ & Histamine $(10 \mu \mathrm{M})$ \\
\hline None (solvent control) & $100^{\mathrm{a}}$ & $100^{\mathrm{a}}$ \\
PD 98059 $(10 \mu \mathrm{M})$ & $47.4 \pm 8.3^{*}$ & $111.3 \pm 9.7$ \\
PD 98059 $(30 \mu \mathrm{M})$ & $28.9 \pm 6.4^{* *}$ & $120.2 \pm 13.6$ \\
PD 98059 $(50 \mu \mathrm{M})$ & $18.2 \pm 5^{* * *}$ & $126.4 \pm 11.2$ \\
SB 203580 $(1 \mu \mathrm{M})$ & $92.4 \pm 8.3$ & $88.6 \pm 12.5$ \\
SB 203580 $(10 \mu \mathrm{M})$ & $78.1 \pm 6.6$ & $80.2 \pm 9.8$ \\
Wortmannin $(0.3 \mu \mathrm{M})$ & $104.4 \pm 12.7$ & $91.1 \pm 10.3$ \\
Wortmannin $(1 \mu \mathrm{M})$ & $116.3 \pm 14.9$ & $86.8 \pm 9.6$ \\
Cimetidine $(3 \mu \mathrm{M})$ & $114.2 \pm 16.8$ & $21.1 \pm 4.2^{* * *}$ \\
\hline
\end{tabular}

${ }^{a}$ Uninhibited cAMP generation by PMA and histamine were $3.1 \pm 0.6$ and $2.6 \pm 0.4 \mathrm{pmol} / 10^{6}$ cells, respectively.

${ }^{*} \mathrm{p}<0.05 ;{ }^{* *} \mathrm{p}<0.01 ;{ }^{* * *} \mathrm{p}<0.001$.

specific inhibitor of PI3 kinase, had no significant effect on the cAMP responses of both PMA and histamine. As expected, the effect of histamine was almost abolished by the histamine $\mathrm{H}_{2}$-receptor antagonist cimetidine.

To confirm the specific involvement of ERK1/2 phosphorylation in the PMA response, Western blot analysis was performed. As shown in figure 3, unstimulated eosinophils expressed both ERK1 and ERK2, but little or no phosphorylated forms of these kinases. Stimulation of the cells with PMA resulted in a rapid phosphorylation of ERK1/2 that peaked in 3-5 min (fig. 3a). Pre-treatment of the cells with the ERK1/2 inhibitor, PD 98059, abolished the response (fig. 3b); thus, confirming the notion that phosphorylation of ERK1/2 is involved in the PMA-stimulated production of cAMP in these cells.

In order to determine whether ROS generation or ERK1/2 phosphorylation came first in the pathway, both DPI and PD 98059 were used in the same immunoblot experiments. As seen in figure $3 \mathrm{~b}$, the PMA-induced ERK1/2 phosphorylation, which was abolished by PD 98059, was completely unaffected by even a high concentration of DPI $(50 \mu \mathrm{M})$. This suggests that ROS production was downstream of ERK1/2 phosphorylation in the signaling pathway. The effectiveness of the PKC inhibitor, Ro 31-8220, in blocking ERK1/2 phosphorylation further confirmed that the effect of PMA was PKC-mediated. 

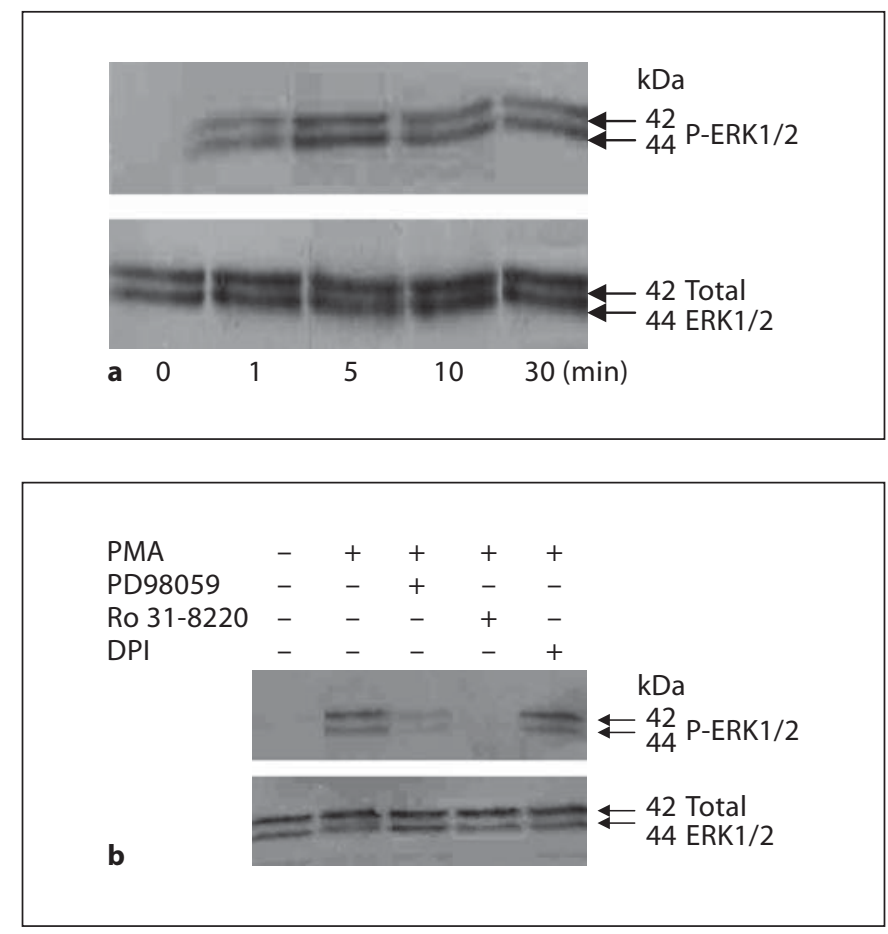

Fig. 3. Western blot analysis of the expression and phosphorylation of ERK1/2 in human eosinophils and the effect of various inhibitors. Time course of PMA-induced ERK1/2 phosphorylation (a). b The effect of inhibitors. Cells were incubated with the inhibitor for 5 min before stimulation with PMA (200 nM). Exposure times for blots were $1 \mathrm{~min}$ for total ERK1/2 and $10 \mathrm{~min}$ for P-ERK1/2 (phosphorylated ERK1/2). Molecular weights of ERK1/2 are in kilodaltons. The figure is representative of 3 other experiments with similar results.

\section{Discussion}

We had previously reported a novel PKC- and ROSdependent mechanism by which PMA can stimulate the production of cAMP in human eosinophils $[13,14]$. In the current study, we have further explored the signaling pathway by investigating the role of ERK1/2 phosphorylation. Our results provide evidence that ERK1/2 phosphorylation is critical to this pathway, and, to the best of our knowledge, this is the first report of the involvement of ERK1/2 phosphorylation in the induction of cAMP in eosinophils, and indeed any other mammalian cell type. This inference is based on the fact that the inhibitor of ERK1/2, PD 98059, inhibited the PMA-induced cAMP response. As this inhibitor did not affect histamine-induced cAMP production, the results further support the notion that the signaling pathway is different from the traditional receptor- $\mathrm{G}_{\mathrm{s}}-\mathrm{AC}-\mathrm{cAMP}$ pathway. Further-

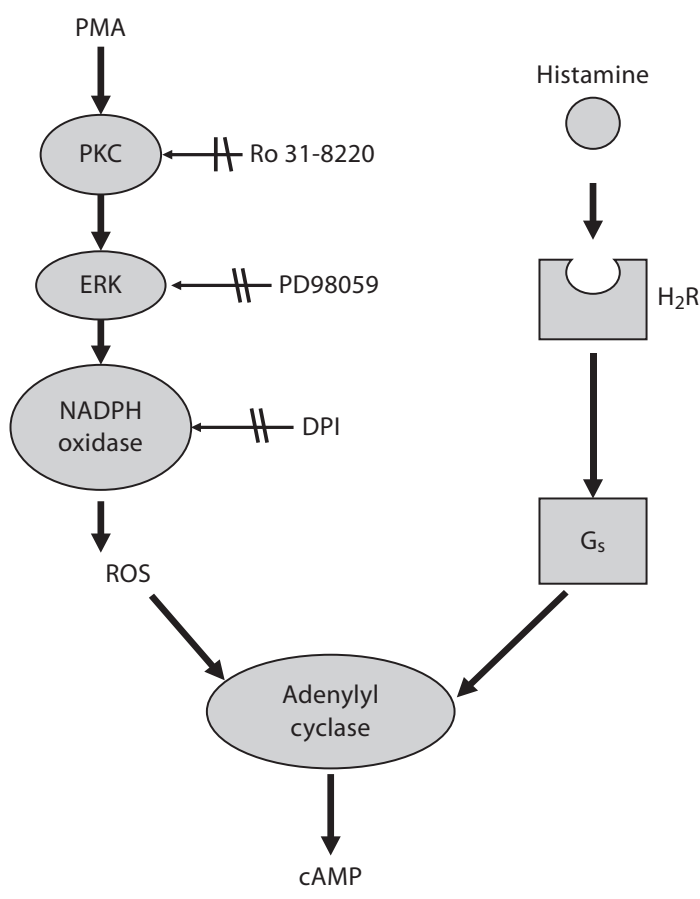

Fig. 4. Hypothetical model describing the involvement of ERK1/2 as well as PKC and ROS in the signaling pathway of PMA-induced stimulation of cAMP production in human eosinophils. $\mathrm{H}_{2} \mathrm{R}=$ Histamine receptor protein. more, 2 other inhibitors - SB 203580, which is the specific inhibitor of p38-MAPK (a kinase that belongs to the same family as ERK1/2), and wortmannin which is a potent inhibitor of the unrelated, but common signaling kinase, PI3 kinase - had no effect on the responses of both PMA and histamine. Thus, it does appear that phosphorylation of ERK1/2 plays a unique and specific role in this pathway. Results from Western blot analysis further confirmed a clear involvement of ERK1/2 phosphorylation, as the ERK1/2 inhibitor PD 98059 that blocked the CAMP production also blocked ERK1/2 phosphorylation. Furthermore, the time course of ERK1/2 phosphorylation $\left(t_{1 / 2} \sim 1 \mathrm{~min}\right)$, which appears to precede that of PMA-induced cAMP accumulation $\left(\mathrm{t}_{1 / 2}=1.7 \mathrm{~min}\right)$ [13], is consistent with a causal relationship between ERK1/2 phosphorylation and cAMP production.

Using a number of specific inhibitors in an attempt to determine the hierarchy in the signal transduction, it was 
further determined that the NADPH oxidase inhibitor, DPI, inhibited PMA-induced cAMP production but not the ERK1/2 phosphorylation, whereas the ERK1/2 inhibitor, PD 98059, inhibited both the PMA-induced cAMP generation and ERK1/2 phosphorylation. This suggests that ROS generation is downstream of ERK1/2 phosphorylation while PKC activation is upstream.

It is perhaps necessary to point out that although the inhibitors used in this study are regarded as specific for the corresponding target enzymes, off-target effects are possible and therefore cannot be ruled out. However, the fact that none of the inhibitors affected histamine-induced $\mathrm{G}_{\mathrm{s}}$-dependent cAMP response strongly supports the existence of the proposed pathway.

The results obtained in this study allow us to propose the signaling pathway depicted in figure 4 , in which PMA-activated PKC phosphorylates ERK1/2, which in turn phosphorylates and activates the NADPH oxidase. The resulting ROS produced ultimately activates AC to generate cAMP.

There is conflicting data in the literature concerning the hierarchical relationship between ERK1/2 phosphorylation and ROS generation in signaling mechanisms [10, 22-25]. The study of Greene et al. [10] on $\mathrm{H}_{2} \mathrm{O}_{2}$-mediated signaling in 5HT-activated rat mesangial cells, have situated ERK1/2 activation downstream of NADPH oxidase activation. A similar sequence of events was also suggested for the involvement of $\mathrm{H}_{2} \mathrm{O}_{2}$ in cytokine gene expression and apoptosis $[22,23]$. Other studies in both animal models and human neutrophils $[24,25]$ have, on the other hand, reported an ERK1/2-dependent activation of $\mathrm{NADPH}$ oxidase, in agreement with our present results. These conflicting observations may be explained by cellspecific differences in the signaling pathways commonly observed across cell types.

The mechanism whereby ERK1/2-dependent generation of ROS may lead to the activation of AC is not clear.
Intracellular or extracellular ROS may either activate the AC directly or indirectly by being converted to other active intermediates. For example, $\mathrm{H}_{2} \mathrm{O}_{2}$ could undergo the Fenton reaction with iron or copper to generate hydroxyl radicals $\left(\mathrm{HO}^{\circ}\right)$, which have been reported to sensitize AC for an increased cAMP response to agonists [26].

Intracellular cAMP is essentially an inhibitory second messenger in eosinophils. It is known to downregulate many eosinophils responses such as degranulation [13, 27], chemotaxis and respiratory burst $[5,28]$. Since PKC activation, ERK1/2 phosphorylation and intracellular ROS generation are all important steps in the signaling mechanisms in cellular activation, the significance of this PKC-ERK-ROS-dependent pathway of cAMP generation may be to act as a counter-regulatory mechanism for terminating responses to cell activation.

\section{Conclusion}

This study has provided evidence suggesting that in addition to PKC activation and ROS generation, ERK1/2 phosphorylation is also involved in the signaling pathway of PMA-induced stimulation of cAMP production in human eosinophils. The novel pathway that we propose may serve as an alternative pathway by which agents that activate PKC , ERK or NADPH oxidase may generate intracellular cAMP independent of the traditional $G_{s}$ and perhaps $\mathrm{G}_{\beta \gamma}$ pathways.

\section{Acknowledgements}

This work was supported by grants No. MR 02/01 and MR 01/04 from the Research Administration Department, Kuwait University, Kuwait. We are grateful to Ms. Elizabeth Philips for her excellent technical assistance and to Prof. Islam Khan for advice on Western blotting.

\section{References}

1 Gleich GJ, Adolphson CR: The eosinophil and bronchial asthma: evidence for a critical role of eosinophils in pathophysiology; in Lenfant C (ed): Interleukin-5: From Molecule to Drug Target for Asthma. New York, Marcel Dekker, 1999, pp 1-37.

2 Adamko D, Lacy P, Moqbel R: Mechanisms of eosinophils recruitment and activation. Curr Allergy Asthma Rep 2002;2:107-116.
Robinson C, Carver JE: Interactions between eosinophils and the airway epithelium. Lung Biol Health Dis 1998;117:263-286.

$\checkmark 4$ Kay AB, Philips S, Robinson DS: A role for eosinophils in airway remodeling in asthma. Trends Immunol 2004;25:477-482.

5 Giembycz MA, Lindsay MA: Pharmacology of eosinophils. Pharmacol Rev 1999;51:213340 .
6 Elsner J, Kapp A: Activation of human eosinophils by chemokines. Chem Immunol 2000;76:177-207.

7 Babior BM: NADPH oxidase. Curr Opin Immunol 2004;16:42-47.

8 Hsu HY, Wen MH: Lipopolysaccharidemediated reactive oxygen species and signal transduction in the regulation of interleukin-1 gene expression. J Biol Chem 2002; 277:22131-22139. 
$>9$ Abe J, Berk BC: Reactive oxygen species as mediators of signal transduction in cardiovascular disease. Trends Cardiovasc Med 1998;8:59-64.

-10 Greene EL, Houghton O, Collinsworth G, Garnovskaya MN, Nagai T, Sajji T, Bheemanathini V, Grewal JS, Paul RV, Raymond JR: 5-HT2A receptors stimulate mitogen-activated protein kinase via $\mathrm{H}_{2} \mathrm{O}_{2}$ generation in rat renal mesangial cells. Am J Physiol Renal Physiol 2000;278:F650-F658.

11 Yu C, Rahmani M, Dent P, Grant S: The hierarchical relationship between MAPK signaling and ROS generation in human leukemia cells undergoing apoptosis in response to the proteasome inhibitor bortezomib. Exp Clin Res 2004;295:555-566.

$\checkmark 12$ Suzuki Y, Youshimaru T, Matsui T, Inoue T, Niide O, Nunomura S, Ra C: FceRI signaling in mast cells activates intracellular production of hydrogen peroxide: role in the regulation of calcium signals. J Immunol 2003;171: 6119-6127.

$>13$ Ezeamuzie CI, Taslim N: Protein kinase C activation inhibits eosinophil degranulation through stimulation of intracellular cAMP. Br J Pharmacol 2004;143:725-732.

14 Ezeamuzie CI, Taslim N: Reactive oxygen species mediate phorbol ester-stimulated cAMP response in human eosinophils. Eur J Pharmacol 2006;543:174-180.

15 Laudanna C, Campbell JJ, Butcher EC: Elevation of intracellular cAMP inhibits RhoA activities and intergrin-dependent leukocyte adhesion induced by chemoattractants. J Biol Chem 1997;272:24141-24144.
16 Cano E, Mahadevan LC: Parallel signal processing among mammalian MAPKs. Trends Biochem Sci 1995;20:117-122.

17 Seger R, Krebs EG: The MAPK signaling cascade. FASEB J 1995;9:726-735.

18 Hewson CA, Edbrooke MR, Johnston SL: PMA induces the MUC5AC respiratory mucin in human bronchial epithelial cells via PKC, EGF/TGF-alpha, RAS/Raf, MEK, ERK and Sp1-dependent mechanisms. J Mol Biol 2004;344:683-695.

19 Hasegawa J, Takekoshi S, Nagata H, Osamura RY, Suzuki T: Sevoflurane stimulates MAP kinase signal transduction through the activation of PKC-alpha and betaII in fetal rat cerebral cortex cultured neurons. Acta Histochem Cytochem 2006;39:163-172.

20 Ezeamuzie CI, Philips E: Adenosine $\mathrm{A}_{3}$ receptors on human eosinophils mediate inhibition of degranulation and superoxide anion release. Br J Pharmacol 1999;127:188194.

21 Hansel TT, De Vries JM, Iff T, Ris S, Wandzilak M, Bezt S, Blaser K, Walker C: An improved immunomagnetic procedure for the isolation of highly purified human blood eosinophils. J Immunol Methods 1991;145: 105-110.

22 Junn E, Lee KN, Ju HR, Han SH, Im JY, Kang HS, Lee TH, Bae YS, Ha KS, Lee ZW, Rhee SG, Choi I: Requirement of hydrogen peroxide generation in TGF- $\beta 1$ signal transduction in human fibroblast cells: involvement of hydrogen peroxide and calcium in TGF$\beta 1$-induced IL-6 expression. J Immunol 2000;165:2190-2197.
23 Carvalho H, Evelson P, Sigaud S, GonzalevFlecha B: Mitogen-activated protein kinases modulate hydrogen-peroxide-induced apoptosis in primary rat alveolar epithelial cells. J Cell Biochem 2004;92:502-513.

24 Okai Y, Sato EF, Higashi-Okai K, Inoue M: Enhancing effect of the endocrine disrupter para-nonylphenol on the generation of reactive oxygen species in human blood neutrophils. Environ Health Perspect 2004;112: 553-556.

25 Park J, Kim EJ, Kwon KJ, Jung Y, Moon C, Lee SH, Baik EJ: Neuroprotection by fructose-1,6-biphosphate involves ROS alteration via p38 MAPK/ERK. Brain Res 2004; 1026:295-301.

26 Tan CM, Xenoyannis S, Feldman RD: Oxidant stress enhances adenylyl cyclase activation. Circ Res 1995;77:710-717.

$>27$ Kita H, Abu-Ghazaleh I, Gleich GJ, Abraham RT: Regulation of Ig-induced eosinophil degranulation by adenosine $3^{\prime}, 5^{\prime}$-cyclic monophosphate. J Immunol 1991;146:27122718

28 Ezeamuzie CI, Zaida G, Mathew M, Philips E, Gopinath S, Owunwanne A: Eosinophils as target of the anti-inflammatory effect of salmeterol: demonstration with indium-111labeled eosinophils. Med Princ Pract 2001; 10:83-88. 